\section{We are going through changes: simple techniques to keep yourself and team engaged during times of change}

\section{Alan Robinson \\ WHY IS IMPLEMENTING CHANGE SO EMOTIONALLY DEMANDING?}

The veterinary owner or practice manager faces certain challenges in the role of business director. His/her role is often 'non-veterinary' in what the culture perceives as clinical environment. They have often been promoted or brought in (often over others) to specifically create change as well as facing all the typical problems of a leader within a professional organization. These problems are not personally aimed at veterinary practice managers but inherent in professional businesses:

- A shortfall in management skills - change calls for training, mentoring and encouragement skills

- The risk of failure and being viewed as incompetent

- Letting go of control and micromanagement

- Time and resources - or rather lack of them

- Employees questioning the new culture and therefore the competence of the management

- Getting all practice owners/partners/directors agreeing to change

- Lack of external perspective and 'big picture' orientation.

The emotional change reaction is typically:

- Denial and excuses due to fear

- Physiological sympathetic response to danger of 'fight or flight' with anger, frustration and resistance. Followed by

- Rational justification based on past conceptual beliefs with entrenched positions. The process often gets stuck between steps 2 and 3 unless there is a change in state that leads to

- Safety and acceptance. Followed by ...

- A change in behaviour and new actions.

All of this is due to cognitive and emotional overload, being overwhelmed, ambiguity and conflict. Essentially people feel threatened and do not feel safe. This instigates the 'normal' autonomic adaptive sympathetic 'fight, flight or freeze' defence system response to danger from environment, events, thoughts or people, that is, change.

\section{STRESSED VETERINARY SURGEONS DO NOT CHANGE}

We see behavioural symptoms of paralysis by analysis, poor performance, procrastination, pointless meetings and planning, blame, 'them and us', 'going native', 'loose cannons', withdrawal 'into the bunker' and reactivity not ideal for change management - on top of their already stressful work.

If you want people to change, people need to feel safe - psychologically and physiologically safe (in flow) and environmentally and relationally safe (trust). This talk discusses some strategies to maintain a culture of safety in which flow and trust enable change and team engagement and keep managers healthy.

\section{KEY LEARNING OBJECTIVES}

- Understand the physiological 'state' that change induces and how it prevents adaptive behaviour

- How to regulate your own physiological state (flow) in the face of change and also co-regulate others to enable change

- How to build trust as a manager and maintain trust within your team

\section{MULTIPE CHOICE QUESTIONS}

1. The change curve typically follows which process?

(A) Denial, emotional response, rational justification, acceptance, change

(B) Change, rational justification, acceptance, denial, emotional response

(C) Denial, emotional response, rational justification, change, acceptance

(D) Denial, change, emotional response, rational justification, acceptance

2. The physiological sympathetic response invoked by threat and being not safe does NOT typically result in which behaviours?

(A) Paralysis by analysis, poor performance, procrastination

(B) Productive meetings and clear planning

(C) Blame, 'them and us', 'going native' 'loose cannons'

(D) Withdrawal 'into the bunker' and reactivity

3. People experiencing change often initially undergo cognitive and emotional overload, feeling overwhelmed, ambiguity and conflict. How should this be managed?

(A) Give people as little information as possible

(B) Force people to accept the change with incentives

(C) Manage your own physiological state so you can co-regulate others

(D) Have lots of meetings telling people about the benefits of change 